\title{
SOME THERMAL EFFEGTS OF BUBBLES IN TEMPERATE GLACIER ICE
}

\author{
By C. F. Raymond \\ (Geophysics Program, University of Washington, Seattle, Washington 98ı 95, U.S.A.)
}

\begin{abstract}
Gas bubbles in core samples from the Blue Glacier, Washington, were observed to be partially filled with liquid. The time and spatial dependence of liquid content in the bubbles demonstrates that the in situ liquid content of the bubbles was small and liquid appeared in the bubbles as a consequence of heat flow into the sample after collection. An effective bulk heat capacity for wet bubbly ice is derived and used to analyze the relaxation process and it is shown that the warming of samples is controlled by an effective heat capacity two or more orders of magnitude larger than for pure ice. The relaxation process presents a practical difficulty for measurement of in situ water content from core samples and the behavior of the bubbles indicates that at positions in a temperate glacier where bubbles have pressure in excess of the ice stress, bubbles may control the ice temperature and significantly restrict water flow through veins.

RÉsumÉ. Quelques effets thermiques des bulles dans la glace de glacier tempéré. On a remarqué que des inclusions gazeuses dans des échantillons provenant du Blue Glacier dans le Washington, étaient partiellement remplies de liquide. La variation de la teneur en liquide des bulles dans le temps et l'espace prouve que cette teneur était faible dans la glace "in situ" et que l'apparition du liquide dans les bulles est une conséquence d'un flux de chaleur dans l'échantillon, après un prélèvement. Une capacité calorifique moyenne effective pour de la glace bulleuse humide en est déduite et est utilisée pour analyser le processus de relaxation. On montre que le réchauffement des échantillons est réglé par une capacité calorifique effective dont l'ordre de grandeur est deux fois ou plus, supérieur à celle de la glace pure. Le processus de relaxation engendre une difficulté pratique pour la mesure de la teneur en eau "in situ", à partir de carottes-échantillons, et le comportement des bulles indique que, pour des positions dans un glacier tempéré où les bulles ont une pression supérieure à la contrainte régnant dans la glace, les bulles peuvent contrôler la température de la glace et réduire de manière significative la circulation de l'eau dans les réseaux intraglaciaires.
\end{abstract}

Zusammenfassung. Einige thermische Wirkungen von Blasen im Eis temperierter Gletscher. Gasblasen in Bohrproben aus dem Blue Glacier, Washington, erwiesen sich als teilweise flüssigkeitsgefült. Das zeitliche und räumliche Auftreten flüssigen Inhalts in den Blasen zeigt, dass in situ der Flüssigkeitsgehalt der Blasen gering war und erst als Folge des Wärmeflusses nach der Probeentnahme auftrat. Für feuchtes, blasiges Eis und eine effektive Gesamtwärmekapazität hergeleitet und zur Analyse des Relaxationsprozesses benutzt. Es zeigt sich, dass die Erwärmung von Proben durch eine effektive Wärmekapazität gesteuert wird, die zwei oder mehr Grössenordnungen über der für reines Eis liegt. Der Relaxationsprozess erschwert praktische die in-situ-Messung des Wassergehaltes von Bohrproben. Das Verhalten der Blasen weist darauf hin, dass an jenen Stellen in einem temperierten Gletscher, wo der Druck in den Blasen die Spannung des Eises übersteigt, die Blasen die Eistemperatur bestimmen und den Wasserfluss durch Adern merklich einschränken können.

\section{INTRODUCTION}

Temperate glacier ice is a material normally containing three phases: solid, liquid, and gas. Based on recent theoretical discussions of temperate glacier ice, one expects the liquid phase to be in a network of veins lying along three-grain intersections (Nye and Frank, I973) or perhaps in lenses on grain boundaries (Nye and Mae, 1972) with the gas phase in bubbles some of which touch the veins and the rest of which are isolated in the interior of crystals (Lliboutry, I97I). Observations have been made on core samples collected from the Blue Glacier, Washington, which largely confirm this view of temperate glacier ice (Raymond and Harrison, 1975). One interesting feature observed in the samples but not considered by these authors in these theoretical discussions was the existence of liquid in gas bubbles isolated from the veins. A similar observation was made by Bader (1950) on ice cut from crevasse walls in Malaspina Glacier, Alaska. In this paper the origin of liquid in isolated gas bubbles is re-examined and it is proposed that in some circumstances bubbles isolated in the interior of crystals can have a pronounced effect on ice temperature and the behavior of the liquid phase in temperate glaciers.

\section{Observations}

The coring was done in August 1972 at a site slightly below the usual late summer snow line and close to the 196r location of the bore hole s2 of Shreve and Sharp (1970, p. 67). A 
general description of the glacier is given by Allen and others (1960), LaChapelle (1965), Corbató (1965) and Harrison (1972). Cores were collected to a depth of $60 \mathrm{~m}$.

Observations were made with a stereoscopic microscope on slabs about 50 to $100 \mathrm{~mm}$ thick cut crossways from cores of o. $15 \mathrm{~m}$ diameter. The microscope was fitted with a reticule eye-piece and a beam splitter with a $35 \mathrm{~mm}$ camera mount which allowed simultancous visual examination and photography. Observations were made in a snow cave with illumination from an incandescent light and were usually started within several minutes after a core had been raised to the glacier surface.

An isolated bubble can be described in terms of a bubble cavity partially filled with liquid and partially with gas (Fig. I). The bubble cavity usually had disk-like shape. The gas bubble was usually spherical. Bader (1950, p. 449, figs 2 and 3 ) has given a good description of the range of shapes. Bubbles with a large ratio of water volume to air volume tended to have tapered edges, thus giving a saucer shape with a hub containing the air bubble. The disk shapes were aligned within any single ice crystal. Thin-section measurements have shown that the disks are perpendicular to the $c$-axis (personal communication from W. B. Kamb).

The ratio $r$ of the maximum dimension of the bubble cavity perpendicular to the line of sight to the diameter of the air bubble in it was measured as a crude indicator of the relative amounts of liquid and gas present in a bubble. It was found that the amount of liquid associated with the isolated bubbles increased with time (e.g. Fig. 2) and at any given time bubbles near the external surface of a sample contained more liquid than those more in the interior (e.g. Fig. 3). These results indicate that the in situ water content of the bubbles is small or zero and that the liquid appears as a consequence of a relaxation process caused by removing the ice from the glacier.

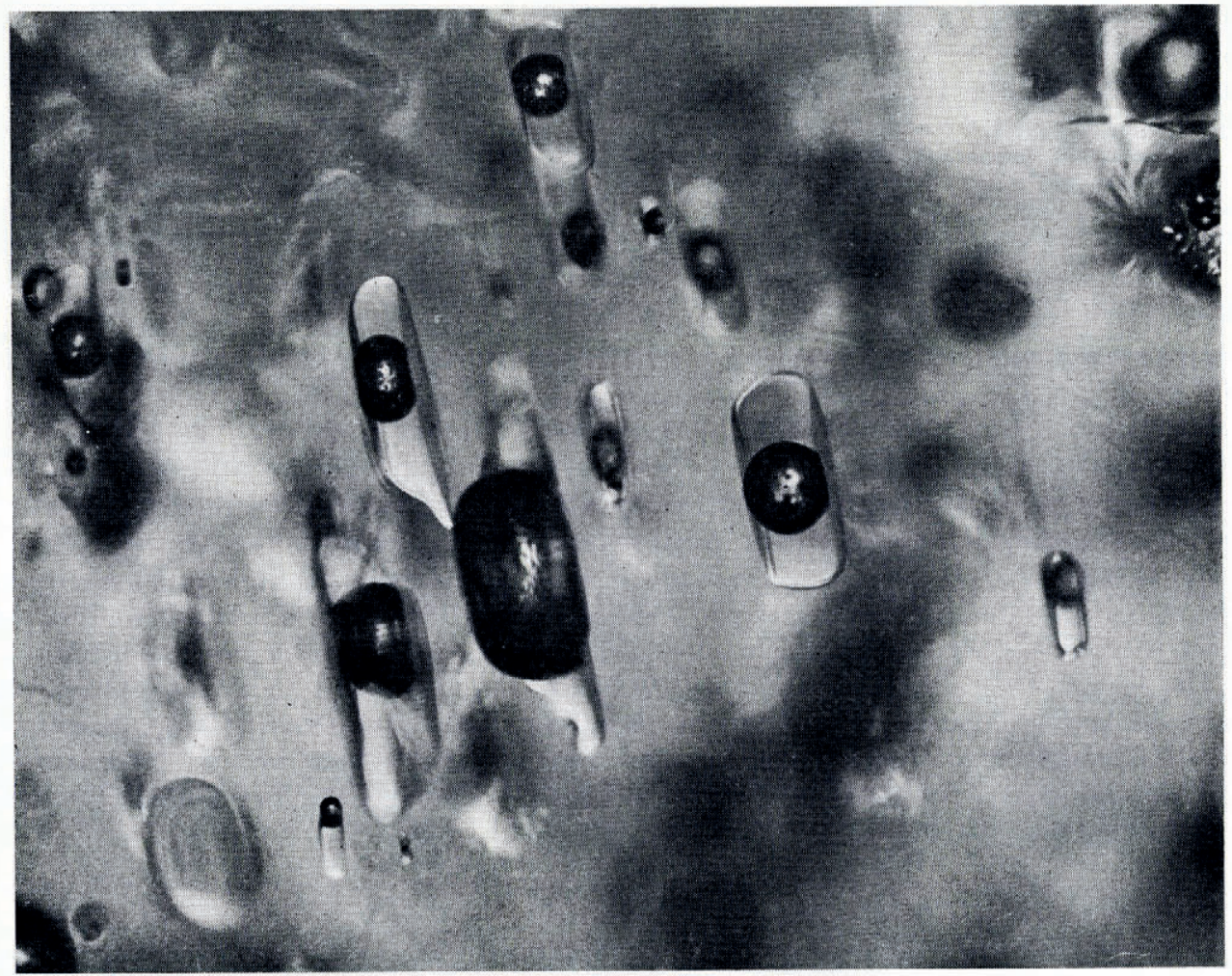

Fig. I. Isolated bubbles containing liquid in an ice sample collected from $14 \mathrm{~m}$ depth. Magnification approximately $22 \times$. 


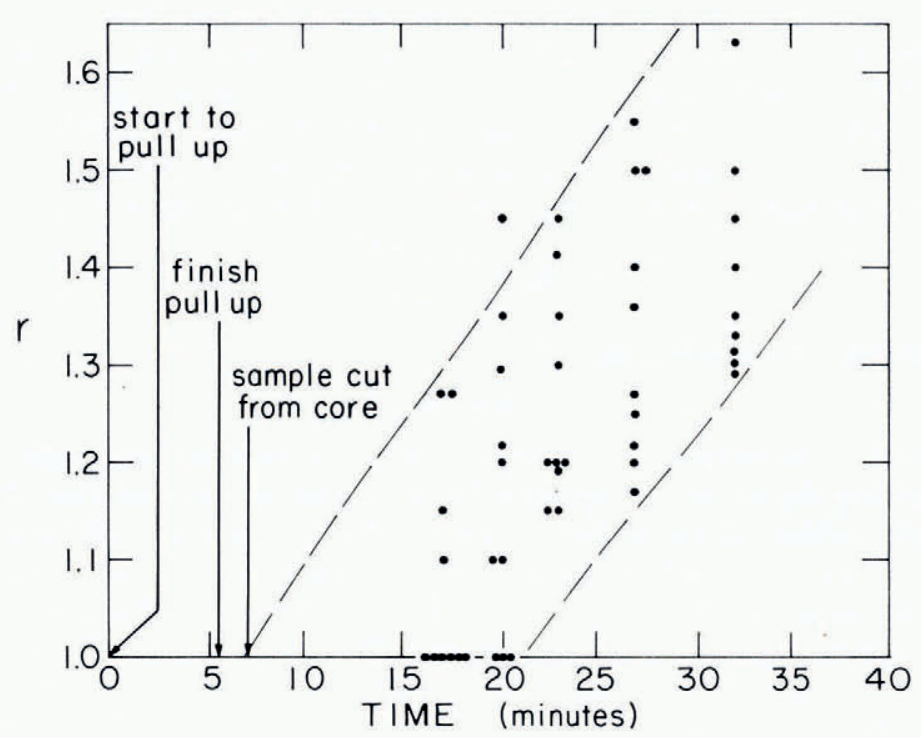

Fig. 2. Time dependence of water content in bubbles lying about $6.5 \mathrm{~mm}$ into the sample. The sample was collected from a depth of $56.8 \mathrm{~m}$ and was composed of coarse bubbly ice with grain size about $30 \mathrm{~mm}$ and bubble diameters averaging about $0.5 \mathrm{~mm}$. The ratio $r$ is the maximum cavity dimension perpendicular to the line of sight divided by the diameter of the included air bubble.

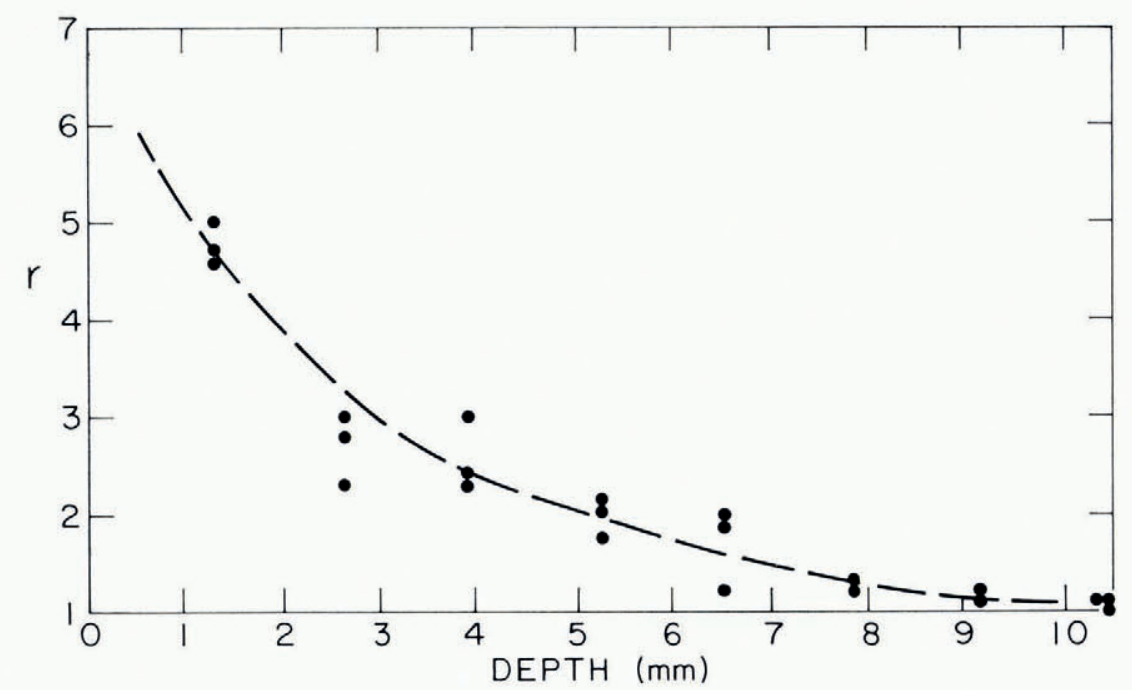

Fig. 3. Space dependence of water content in bubbles 40 min after cutting sample 56.8 from the core. The ratio $r$ is the maximum cavity dimension perpendicular to the line of sight divided by the diameter of the included air bubble. 


\section{THEORY}

In the process of collecting the sample from the glacier, the pressure on the sample surface is lowered to atmospheric pressure within the course of several minutes, but the pressure in bubbles isolated from veins is maintained close to the in situ value. If the external surface is wet, as in practice it is, then the surface is warmer than the bubbles and heat flows to them to cause melting. This could explain the progressive increase of liquid volume with time.

A quantitative treatment of the process can be based on the equation of thermal diffusion

$$
\nabla^{2} T=\frac{\mathrm{I}}{\kappa} \frac{\partial T}{\partial t} .
$$

The thermal diffusivity $\kappa$ is given by

$$
\kappa=K / \rho c
$$

where $K$ is thermal conductivity, $\rho$ is density, and $c$ is specific heat capacity. One could contemplate solving Equations (I) given $\kappa$ for ice, and the temperature $T$ on the sample surface and each bubble cavity surface. This would require very tedious measurements of bubble configuration and would lead to a mathematically impractical problem. Instead one can take the following statistical approach, which is similar to that employed in thermodynamic calculations applied to sea ice (Schwerdtfeger, I963; Maykut and Untersteiner, 1971). A bulk diffusivity can be defined for the bubbly ice which takes into account a large effect due to changing amounts of liquid in bubbles and the corresponding heat of phase change. Equations (I) can then be solved using this bulk diffusivity with the initial condition that initial temperature $T_{\mathrm{i}}$ be equal to the in situ temperature at the depth of origin of the sample and the boundary condition that the sample surface is at a temperature $T_{\mathrm{s}}$ appropriate to a wet surface at atmospheric pressure. One might expect that the amount of liquid in a bubble can be related to its temperature, in which case the above temperature solution can be used to predict the water content of bubbles as a function of position and time. Conversely, the observed water contents can be interpreted in terms of temperature and checked against the predicted temperature. The basis for this approach is developed in this section.

\section{Temperature of a bubble}

Consider a bubble which is cold enough that no liquid is present. Let $T_{0}, p_{0}$, and $V_{0}$ be the Kelvin temperature, air pressure excluding $\mathrm{H}_{2} \mathrm{O}$ vapor, and volume of the bubble when liquid phase first appears as it is heated quasi-statistically.

First assume that there is no significant strain in the ice surrounding the bubble during the thermal relaxation, so the volume of the bubble changes only as a result of melting. Further assume that the volume of liquid $V_{w}$ produced by melting is not significantly affected by any gases dissolved in it, in which case $V_{\mathrm{w}}$ was produced by melting a mass of ice $\rho_{\mathrm{w}} V_{\mathrm{w}}$, where $\rho_{\mathrm{w}}=\mathrm{I} .00 \mathrm{Mg} \mathrm{m}^{-3}$ is the density of water. Consequently, the bubble volume is

$$
V_{\mathrm{b}}=V_{\mathrm{o}}+\rho_{\mathrm{w}} V_{\mathrm{w}} / \rho_{\mathrm{i}}
$$

and gas occupies a volume

$$
V_{\mathrm{a}}=V_{\mathrm{b}}-V_{\mathrm{w}}=V_{\mathrm{o}}+\left(\rho_{\mathrm{w}} / \rho_{\mathrm{i}}-\mathbf{I}\right) V_{\mathrm{w}}
$$

where $\rho_{\mathrm{i}}=0.9^{\mathrm{I}} 7 \mathrm{Mg} \mathrm{m}^{-3}$ is the density of ice.

Second, assume that no air molecules are exchanged with the ice, but a volume $\alpha V_{\mathrm{w}}$ is dissolved in the liquid, where $\alpha$ is the volume solubility of atmospheric air in water and has a value of 0.029 for equilibrium saturation at $0^{\circ} \mathrm{C}$. The gas law gives

$$
p_{0} V_{\mathrm{o}} / R T_{\mathrm{o}}=p_{\mathrm{a}}\left(V_{\mathrm{a}}+\alpha V_{\mathrm{w}}\right) / R T
$$

where $p_{\mathrm{a}}$ is the partial pressure of air. 
Third, assume that there are no soluble impurities in the bubble other than atmospheric air, in which case the temperature of the bubble for $T_{0} \leqslant T<\delta$ is given by

$$
T=\delta-\beta^{\prime} p_{\mathrm{a}}
$$

where $\delta=0.0100^{\circ} \mathrm{C}$ is the triple-point temperature and $\beta^{\prime}=0.0098 \mathrm{deg}$ bar $^{-1}$ represents the combined effects of the Clausius-Clapeyron slope (0.007 $4 \mathrm{deg} \mathrm{bar}^{-1}$ ) and pressuredependent solubility of atmospheric air ( $0.0024 \mathrm{deg}$ bar $^{-1}$ assuming equilibrium saturation). Equation (5) neglects compositional change of the air with pressure caused by the different solubilities of $\mathrm{N}_{2}$ and $\mathrm{O}_{2}$, a slight difference in the partial pressure of water vapor and the triple-point pressure, curvature of the wall of the bubble, and possible effects of nonhydrostatic stress in the wall of the bubble. Furthermore, to be precise one must recognize that any given bubble is probably not at the same temperature over its complete boundary, because of location-dependent surface curvature and non-hydrostatic stress and the possibility of impurity-concentration gradients in the liquid. However, these effects are small.

The water volume $V_{\mathrm{w}}$ can be calculated as a function of $T$ by substituting Equation (3) into (4) to eliminate $V_{\mathrm{a}}$ and get

$$
V_{\mathrm{w}}=\frac{\rho_{\mathrm{i}} V_{0}}{\left(\rho_{\mathrm{w}}-\rho_{\mathrm{i}}+\alpha \rho_{\mathrm{i}}\right)}\left(\frac{p_{\mathrm{o}}}{p_{\mathrm{a}}} \frac{T}{T_{\mathrm{o}}}-\mathrm{I}\right) .
$$

Substitution of Equation (5) into this gives

$$
V_{\mathrm{w}}=\frac{\rho_{\mathrm{i}} V_{0}}{\left(\rho_{\mathrm{w}}-\rho_{\mathrm{i}}+\alpha \rho_{\mathrm{i}}\right)}\left(\frac{\delta-T_{0}}{\delta-T} \frac{T}{T_{0}}-\mathrm{I}\right) .
$$

From this one can also determine $V_{\mathrm{b}}$ and $V_{\mathrm{a}}$ as a function of $T$ through Equations (2) and (3). One finds

$$
\frac{T_{0}}{T} \frac{\delta-T}{\delta-T_{0}}=\frac{\rho_{\mathrm{w}}-\left(\rho_{\mathrm{w}}-\rho_{\mathrm{i}}\right) \frac{V_{\mathrm{b}}}{V_{\mathrm{a}}}}{\rho_{\mathrm{i}}\left[\mathrm{I}+\alpha\left(\frac{V_{\mathrm{b}}}{V_{\mathrm{a}}}-\mathrm{I}\right)\right]} .
$$

When $T_{0}$ is known, then $V_{\mathrm{b}} / V_{\mathrm{a}}$ provides a sensitive measure of temperature in the range $T_{0}$ to $\delta$ where the bubble contains liquid.

\section{Bulk thermal diffusivity of wet bubbly ice}

Now consider a piece of ice of unit bulk mass with many bubbles containing liquid. There are contributions to the total effective heat capacity of this piece from the individual heat capacities of each of the three phases present and the heats associated with transfer of mass between the phases by melting, evaporation, and solution. If the water content is small so that the total mass is closely equal to the ice mass, then the contributions from the water and air can be neglected. Furthermore, the contributions from heats of evaporation and solution are insignificant in comparison with the heat of fusion. In this case the total effective heat capacity can be written

$$
c=c_{\mathrm{i}}+H \sum \frac{\mathrm{d} \rho_{\mathrm{w}} V_{\mathrm{w}}}{\mathrm{d} T}
$$

where $H=3.3 \times \mathrm{IO}^{5} \mathrm{~J} \mathrm{~kg}^{-1}$ is the heat of fusion, $c_{\mathrm{i}}=2 . \mathrm{I} \times \mathrm{IO}^{3} \mathrm{~J} \mathrm{~kg}^{-1} \mathrm{deg}^{-1}$ is the specific heat capacity of pure ice, and the sum is over all of the bubbles. If $T<T_{0}$, there is no water and no contribution from the second term. For $T \geqslant T_{0}$, differentiation of Equation ( 7 ) gives

$$
\frac{\mathrm{d} \rho_{\mathrm{w}} V_{\mathrm{w}}}{\mathrm{d} T}=\frac{\rho_{\mathrm{w}} \rho_{\mathrm{i}} V_{\mathrm{o}}}{\left(\rho_{\mathrm{w}}-\rho_{\mathrm{i}}+\alpha \rho_{\mathrm{i}}\right)}\left\{\frac{\delta-T_{0}}{(\delta-T)^{2}}\left(\frac{T}{T_{\mathrm{o}}}\right)+\frac{\delta-T_{0}}{\delta-T} \frac{\mathrm{I}}{T_{\mathrm{o}}}\right\} \text {. }
$$


In Equation ( Iо) negligible effects from the thermal expansion of the liquid and solid, and temperature dependence of the air solubility have been omitted. If it is assumed that all of the bubbles have the same pressure $p_{0}$ and temperature $T_{0}$, substitution of Equation (ro) into Equation (9) gives

$$
c=c_{\mathrm{i}}\left\{\mathrm{I}+B\left(\frac{T}{T_{0}}\right) \frac{\left(\delta-T_{0}\right)^{2}}{(\delta-T)^{2}}\left[\mathrm{I}+\frac{\delta-T}{T}\right]\right\}
$$

where

$$
B=\frac{H}{c_{\mathrm{i}}\left(\delta-T_{\mathrm{o}}\right)} \frac{\rho_{\mathrm{w}} \rho_{\mathrm{i}}}{\left(\rho_{\mathrm{w}}-\rho_{\mathrm{i}}+\alpha \rho_{\mathrm{i}}\right)} \sum V_{\mathrm{o}} .
$$

Here $\sum V_{0}$ represents the total void volume per unit mass when there is no liquid and can be expressed in terms of the bulk density $\rho$ as

$$
\sum V_{\mathrm{o}}=\frac{\rho_{\mathrm{i}}-\rho}{\rho_{\mathrm{i}} \rho}
$$

and $B$ can be written

$$
B=\frac{H}{c_{\mathrm{i}}\left(\delta-T_{\mathrm{o}}\right)} \frac{\rho_{\mathrm{W}}}{\left(\rho_{\mathrm{W}}-\rho_{\mathrm{i}}+\alpha \rho_{\mathrm{i}}\right)} \frac{\rho_{\mathrm{i}}-\rho}{\rho}=\frac{\mathrm{I} 467 \mathrm{deg}}{\delta-T_{0}}\left(\frac{\rho_{\mathrm{i}}-\rho}{\rho}\right) .
$$

Since $T$ and $T_{0}$ are both within several hundredths of a degree of $\delta, T / T_{0} \approx \mathrm{I}$ and $(\delta-T) / T \ll$ I. Thus Equation (I Ia) can be written approximately as

$$
c=c_{\mathrm{i}}\left(\mathrm{I}+\frac{\theta_{\mathrm{t}^{2}}}{\theta^{2}}\right)
$$

where

$$
\theta_{\mathrm{t}}=\left(\delta-T_{0}\right) B^{1} \quad \text { and } \quad \theta=\delta-T .
$$

This is of the same form as the effective heat capacity of ice containing brine pockets as derived by Schwerdtfeger (1963) and expanded upon by Harrison (1972). In one important respect it is quite different. Briny ice experiences essentially a continuous increase in heat capacity with temperature and a term of form $\theta_{t}^{2} / \theta^{2}$ contributes for all temperatures below the freezing point of the bulk melt water and above the eutectic temperature. In contrast the effect of air bubbles causes a large jump to a high value of heat capacity at $T_{0}$ and then a further increase with temperature. The discontinuity at $T_{0}$ is similar to what happens theoretically in the heating of a water system at constant pressure. If one starts at $T<T_{0}$, addition of heat causes warming of the ice according to the standard specific heat. However, once $T_{0}$ is reached, further addition of heat produces liquid phase but no increase in temperature, and there is a jump to an apparently infinite heat capacity until all of the ice has been melted. Bubbly ice behaves like such a system at constant volume rather than constant pressure, and the jump is to a finite value of heat capacity and the melting occurs over a temperature range.

Schwerdtfeger (1963, table VI) has shown that the thermal diffusivity for dry bubbly ice is given by $\kappa_{0}=1$. I $\mathrm{mm}^{2} \mathrm{~s}^{-1}$. This value is quite insensitive to bulk density or temperature. Once $T \geqslant T_{0}$ and liquid has appeared, there may be some change in $K$, but the very large changes in $c$ predicted by Equations (I I) will be the dominant effect. Thus the bulk diffusivity may be approximated by

for $T \geqslant T_{0}$.

$$
\kappa=\kappa_{0}\left\{\mathrm{I}+\frac{\theta_{\mathrm{t}^{2}}}{\theta^{2}}\right\}^{-\mathrm{I}}
$$


In any real sample of glacier ice it seems likely that all of the bubbles will not have the same pressure $p_{0}$. It is fairly obvious how one could derive a more elaborate version of Equations (12) and (13) which would take account of a distribution in $p_{0}$. The effect of a spread in $p_{0}$ would be to smear out the transition from low to high effective heat capacity. However, this added sophistication seems unwarranted; Equations (12) and (I3) should be adequate when used with an average $p_{0}$ as long as the spread is not large. Also there may be salty liquid at other locations in the ice, such as in veins, lenses, or other liquid inclusions (Harrison, I972; Raymond and Harrison, 1975). Assuming these inclusions are isolated from the bubbles and pressure does not change as a result of melting or freezing in them, then their contribution is given by the analysis of Schwertfeger ( 1963 ) or Harrison (I972) and can be simply added on to the contribution from bubbles.

\section{Calculations}

Properties of sample

The results of the previous section can be used to examine the relaxation of sample 56.8 shown in Figures 2 and 3. The in situ ice temperature at the depth of origin of this sample was $T_{\mathrm{i}}=-0.060^{\circ} \mathrm{C}$ from the measurements of Harrison (1975[b]). Once the sample was collected, its surface was under atmospheric pressure which is about 0.82 bar at the altitude of the core site. Since the surface of the sample was always wet from its own melt water, its surface was at $T_{\mathrm{s}}=0.0029^{\circ} \mathrm{C}$ from Equation (5) which assumes negligible contribution from soluble solids and saturation concentration of atmospheric gases. These are reasonable assumptions in view of the extremely low bulk ionic impurity content of the ice (Harrison and Raymond, 1976) and the thinness of the surface water layer. The actual sample was a disk about $50 \mathrm{~mm}$ thick and $150 \mathrm{~mm}$ in diameter. For the purpose of solution of Equation ( $\mathrm{I}$ ), it is reasonable to assume a slab geometry and neglect the edge effects of the circumferential surface. Densities of coarse bubbly ice samples, which were similar in appearance to sample 56.8 and collected from a similar depth, were measured in the range 0.895 to $0.903 \mathrm{Mg} \mathrm{m}^{-3}$. The density of sample 56.8 should be close to $0.90 \mathrm{Mg} \mathrm{m}^{-3}$.

Unfortunately, reliable measurements of bubble pressure were not made. In the vicinity of the core hole, the vertical strain-rate averaged over the upper $60 \mathrm{~m}$ was small and positive, and represents a vertical velocity difference between the surface and $60 \mathrm{~m}$ depth of o. I $\mathrm{m}$ year $^{-1}$ (Harrison, I975[a]). Also the recent annual balances have not been greatly different from zero with both positive and negative values occurring in the last several years. This indicates that in situ bubble pressure equal to the mean ice stress is reasonable. This is estimated to be 5.82 bar, which represents the sum of atmospheric pressure (o.82 bar) and the weight of the overlying ice $\left(\rho g h \cos ^{2} \alpha=5.00\right.$ bar with $\left.\alpha=4.8^{\circ}\right)$. In this case $T_{0}=-0.047^{\circ} \mathrm{C}$ from Equation (5). However, the glacier thins rapidly up-glacier from the core site, and until recent years it had typically experienced negative annual balances of $\mathrm{I}$ to $2 \mathrm{~m}_{\mathrm{year}}^{-1}$ (LaChapelle, 1965). Since the time scale for adjustment of bubble pressure is unknown, and the history of the ice is complex, there is some possibility of either an over- or under-pressure in the bubbles relative to the present mean ice stress. Since the in situ water content of the bubbles was apparently zero, $T_{\mathrm{i}}=-0.060^{\circ} \mathrm{C}$ represents a lower limit to $T_{0}$ and gives an upper limit to $p_{0}$ of 7.14 bar, which would represent a bubble over-pressure of 1.32 bar. A lower limit to $p_{0}$ is taken to be correspondingly lower than the mean ice stress which gives $4.5^{\circ}$ bar and an upper limit for $T_{0}$ of $-0.034^{\circ} \mathrm{C}$. These assumed limiting values for $p_{0}$ and $T_{0}$ are somewhat arbitrary, but they are probably quite liberal estimates of the possible range. In any case, these limits will be useful in examining how lack of precise values affects the conclusions one can make.

With these properties $\theta_{\mathrm{t}}$ is in the range $\mathrm{I} .2$ to $\mathrm{I} .5 \mathrm{deg}$, which is much large than the corresponding transition temperature of several hundredths to tenths of a degree (Harrison, 1972) associated with brine in the ice. For $T>T_{0}$, the bubbles are the dominant effect. 


\section{Predicted temperature distribution}

Equation (I) was solved for the properties described above with $\kappa$ given by Equation (I 3 ). The solutions were obtained numerically by a simple method given by Carslaw and Jaeger (1959, p. 469-7r). The temperature versus time at $6.5 \mathrm{~mm}$ into the sample is shown in Figure 4 and temperature versus distance after $40 \mathrm{~min}$ is shown in Figure 5. Because of the uncertainty in $T_{0}$, the absolute temperature is also uncertain. For this reason the temperature solutions have been shown relative to $T_{0}$ by plotting $\left(T_{\mathrm{s}}-T\right) /\left(T_{\mathrm{s}}-T_{\mathrm{o}}\right)$.

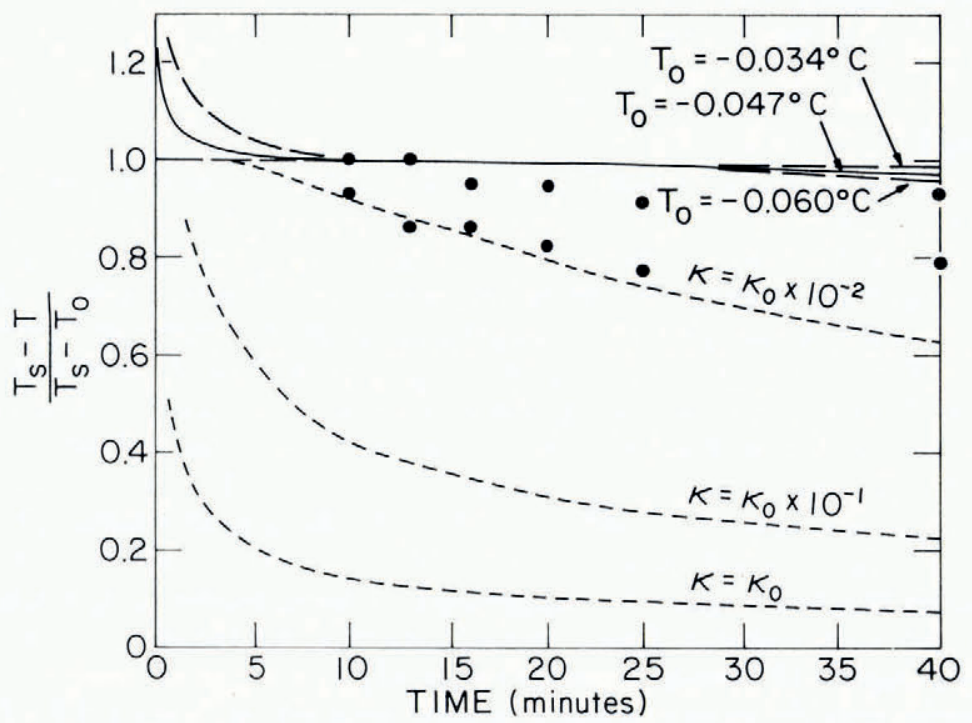

Fig. 4. Temperature versus time predicted at $6.5 \mathrm{~mm}$ inside of sample 56.8 from solution of Equation $(\mathrm{I})$ with bulk diffusivity given by Equation $\left(1_{3}\right)$ and with constant diffusivity of various magnitudes. Solid circles give temperature deduced from measurements of $r$ shown in Figures 2 and 3 , the solid curve in Figure 6 and Equation (8). Here the results are only shown for the minimum and maximum temperature bubbles at each time.

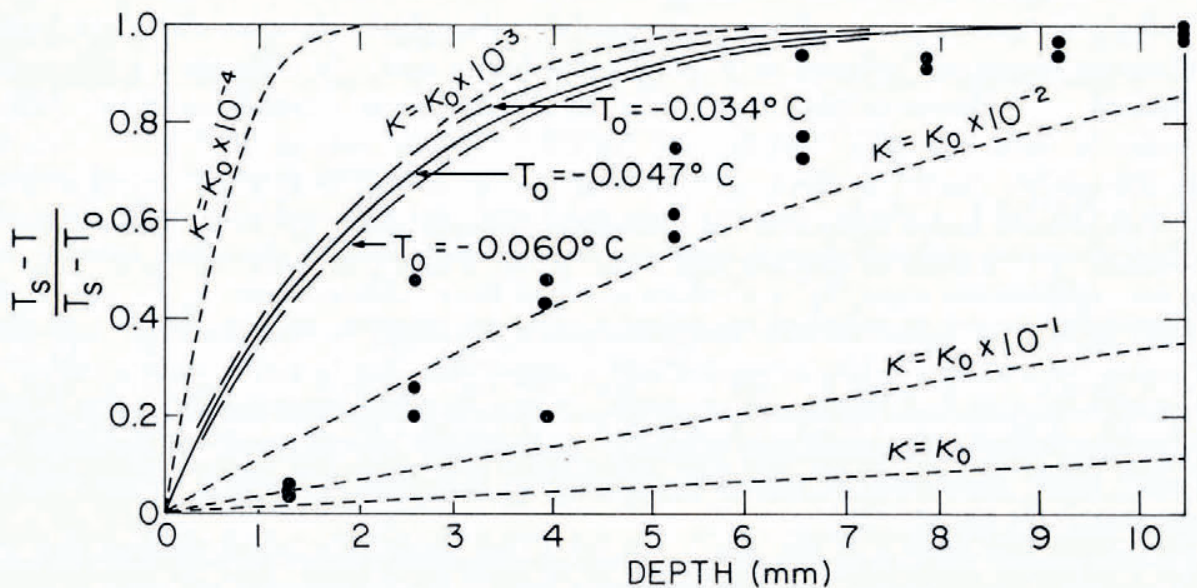

Fig. 5. Spatial dependence of temperature in Sample 56.840 min after being cut from the core. Curves and points are obtained as explained in Figure 4. 
Separate curves are shown for the preferred value of $T_{0}$ and the lower and upper limiting values arrived at above. In Figure 4 the main differences occur during the first io min. On the scale $\left(T_{\mathrm{s}}-T\right) /\left(T_{\mathrm{s}}-T_{0}\right)$, the same initial temperature $\left(T_{\mathrm{i}}=-0.060^{\circ} \mathrm{C}\right)$ plots differently for the different assumptions about $T_{0}$. For $T<T_{0}$, i.e. $\left(T_{\mathrm{s}}-T\right) /\left(T_{\mathrm{s}}-T_{0}\right)>\mathrm{I}, \kappa$ has the value $\kappa_{0}$ for dry bubbly ice and warming is rapid. The different curves converge fairly rapidly to $T=T_{0}$, after which a very much smaller $\kappa$ prevails and the warming is much slower. There is also some difference between the curves on a longer time scale, because $\kappa$ depends on $T_{0}$. In Figure 5 the separation of the curves is small near the surface where the temperature approaches $T_{\mathrm{s}}$ and is known independent of $T_{0}$, and at $8 \mathrm{~mm}$ or deeper where the ice has warmed to $T_{0}$ but has not had time to undergo any additional warming.

The relaxation process cannot be characterized by any single value of $\kappa$, since $\kappa$ is highly temperature dependent by Equation (I3). For $T>T_{0}$ Equation (I3) gives $\kappa$ in the range of about $\mathrm{I} / 5$ oo to less than $\mathrm{I} / 5$ ooo of the value for dry bubbly ice. The lowest values of $\kappa$ occur near the sample surface, where the ice is warmest. For comparison, temperature curves for warming of a homogeneous material assuming several diffusivities are shown on Figures 4 and 5 . For simplicity these curves are shown only for the particular case that $T_{0}=T_{i}$ and calculations were done for a half space (Carslaw and Jaeger, I959, p. 59) rather than a slab of finite thickness. The predicted warming of the wet bubbly ice is approximated reasonably by a homogeneous material with a diffusivity of about $10^{-3}$ of the dry bubbly ice diffusivity.

\section{Estimated temperature of bubbles}

If $r$ measured on bubbles (Figs 2 and 3 ) can be related to $V_{\mathrm{b}} / V_{\mathrm{a}}$, then Equation (8) can be used to determine their temperatures.

For a bubble cavity shaped like a right circular cylinder with height just equal to the diameter of its air bubble, it is easily shown that

$$
V_{\mathrm{b}} / V_{\mathrm{a}}=\frac{3}{2} r^{2} S
$$

where $S=\mathrm{I}$. This could be applied to other rotationally symmetric shapes with an appropriate choice of $S$ to take account of a non-rectangular cross-section, an air bubble with diameter smaller than the height, or a non-spherical air bubble. Occasionally bubble cavities were seen along a line of sight perpendicular to the axis of rotation and the shape could be clearly discerned and $S$ could be evaluated by numerical integration. This was also done for the sketches shown by Bader (1950, p. 449). The results are shown graphically in Figure 6. For most shapes $S$ is between 0.5 and 0.8 with 0.6 to 0.7 being most common, so that $V_{\mathrm{b}} / V_{\mathrm{a}} \approx r^{2}$.

An important constraint on $V_{\mathrm{b}} / V_{\mathrm{a}}$ is given by Equations (2) and (3) which show $V_{\mathrm{b}} / V_{\mathrm{a}} \rightarrow$ $\rho_{\mathrm{w}} /\left(\rho_{\mathrm{w}}-\rho_{\mathrm{i}}\right)=\mathrm{I} 2.03$ in the limit of large $V_{\mathrm{w}}$. Equation (8) shows this limit is reached as $T \rightarrow \delta$. In the case of the samples, this limit is not reached because bubbles cannot get any warmer than $T_{\mathrm{s}}=0.002^{\circ} \mathrm{C}$ and Equation (8) gives an upper limit for $V_{\mathrm{b}} / V_{\mathrm{a}}$ in the range 9.5 to 10.4 depending on which value of $T_{0}$ is taken. The largest value of $r$ ever observed was about 6, and in Figure 3 extrapolation of $r$ to the sample surface gives $r$ about 6.5 to 7 . This suggests that $V_{\mathrm{b}} / V_{\mathrm{a}} \approx$ io for $r=7$.

The solid curve in Figure 6 was chosen as a relationship between $V_{\mathrm{b}} / V_{\mathrm{a}}$ and $r$ which is reasonably compatible with the above observational and theoretical considerations. This curve was used to deduce the temperatures of bubbles and the results corresponding to the data of Figures 2 and 3 are shown in Figures 4 and 5 .

The particular data shown in Figures 2 and 3 were measured on bubbles viewed at skew angles, which precluded a direct assessment of their shapes or $V_{\mathrm{b}} / V_{\mathrm{a}}$. In view of the considerable variety and complicated shapes of bubble cavities, the temperature results are somewhat uncertain. This is especially so for those measurements with $r$ larger than about 2. 


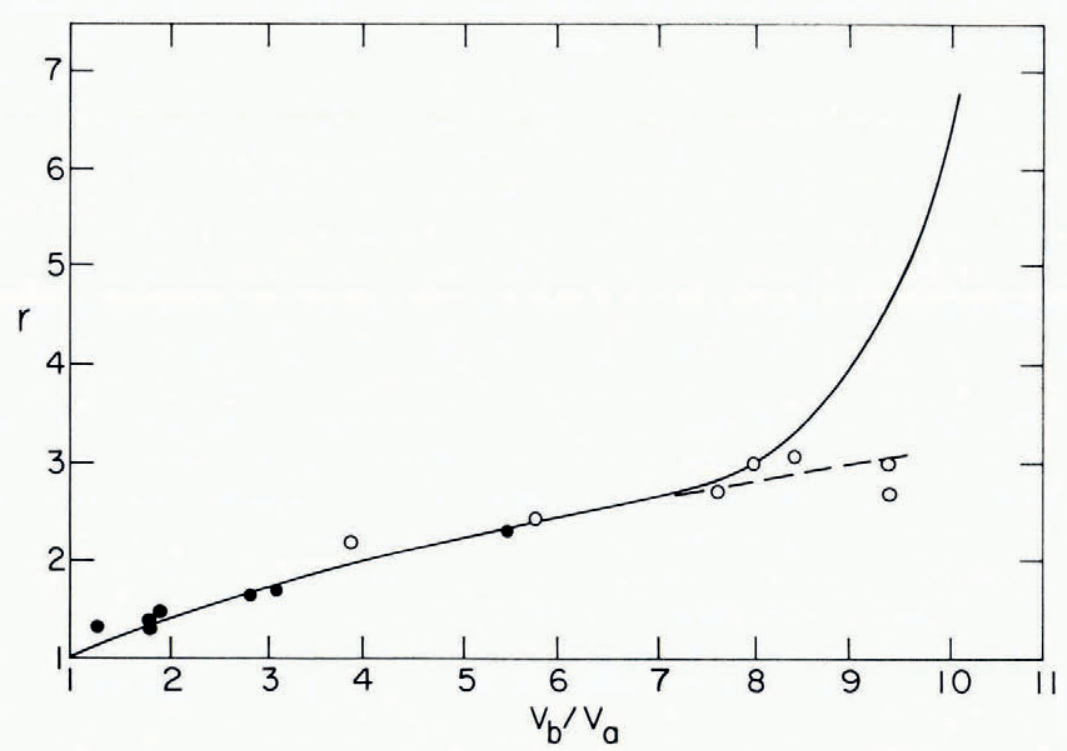

Fig. 6. Relationship between $r$ and $V_{\mathrm{b}} / V_{\mathrm{a}}$. Solid points estimated from present observations. Open points estimated from sketches of Bader $\left(195^{\circ}\right)$. Dashed curve shows $V_{\mathrm{b}} / V_{\mathrm{a}}=r^{2}$ and solid curve shows relationship actually assumed for calculations,

\section{Discussion}

\section{Interpretation of calculations}

The theoretical pattern of temperature can be compared with the temperatures deduced from liquid content of bubbles. The distance into the sample below which bubbles have not experienced significant melting is predicted quite well. On the other hand bubbles close to the sample surface appear to contain more water and be warmer than expected. This may arise from an error in the assumed relationship between $r$ and $V_{\mathbf{b}} / V_{\mathbf{a}}$ caused by the uncertainty in bubble cavity shape. Another contributing factor arises from the statistical nature of the theoretical treatment. It should give a reasonable average temperature at each level in the sample, but one could expect significant local fluctuations from the average on the scale of the spacing bubbles (several millimeters). Since observation of a bubble requires that it be not obscured by other bubbles, the measurements may be biased toward those bubbles which are also more directly exposed thermally to the sample surface and therefore those which warm most rapidly. Although these difficulties preclude a rigorous test of the theoretical treatment, the comparisons in Figures 4 and 5 support the hypothesis that liquid appears in the bubbles as a consequence of heat flow from the sample surface, and that the heating of the sample is controlled by an effective heat capacity which is two or more orders of magnitude larger than that for dry bubbly ice.

Bader (1950) suggested that the liquid he observed in the ice of the Malaspina Glacier was produced in a gradual process proceeding concurrently with the slow natural unloading of the ice by ablation. He assumed that the pressure in air bubbles was relaxed and the temperature maintained at the so-called "pressure melting point" mainly by melting in the bubbles with mechanical effects being less important. Paterson (I97I) has pointed out that over much of the depth of the Athabasca Glacier, the heat generated by internal deformation is inadequate to maintain pure ice at the "pressure melting point" as the ice is unloaded by ablation. This may be characteristic of most glacier ablation areas. The process envisioned by Bader (1950) would even require much more heat because of the much higher effective 
heat capacity of wet bubbly ice. It therefore seems likely that most of the liquid observed by Bader originated by conduction of heat into the sample ice when it became close to the glacier surface or after it was collected, the origin of the heat being external rather than internal to the glacier. This would happen as a consequence of an over-pressure in the bubbles of the near surface Malaspina ice. Such over-pressure is expected in an ablation area and was reported by Bader (1950) for the Malaspina, and Coachman and others (1956) on Storglaciären.

\section{Effect of measurement of water content}

The thermal relaxation caused by the bubbles presents a complication for measurement of a meaningful in situ water content on core samples collected from depth. Figures 2, 3 and 6 show that an amount of liquid equal to several times the original air volume can be produced in the surface layers of an ice sample on a time scale of minutes to tens of minutes. This could cause significant error in delayed measurements on small samples with large ratios of surface area to volume.

\section{Consequences for glacier temperature}

Paterson (I97I) has argued that bubbles may be the primary influence on temperature in parts of the Athabasca Glacier. The concept of a high effective heat capacity supports Paterson's conclusion. The very high effective heat capacity of the bubbly ice once the temperature reached $T_{0}$ means in effect that $T_{0}$ is an approximate upper limit to the ice temperature. In a zone where ice is being unloaded by ablation or vertical strain-rate and bubbles have a pressure in excess of the ice mean stress, the bubbles will force the ice temperature to be lower than the "pressure melting curve" commonly assumed for temperature in a temperate glacier. If there is any liquid in the ice (that is the ice is temperate in the sense of Lliboutry, I97 I, p. I6), it will tend to be in the air bubbles. Liquid inclusions not containing gas such as veins on grain edges or other types would tend to exist at pressures equal to the ice stress (Nye and Mae, I972). Such inclusions could continue to exist in the presence of bubbles with over-pressure only if the over-pressure in the bubbles is balanced by the concentration of impurities in the liquid inclusion. Under these conditions the temperature of the ice would be relatively insensitive to changes in liquid, impurity, or sensible-heat content. Instead it would be controlled by other processes which could affect the bubble pressure and correspondingly $T_{0}$, such as strain in the ice around the bubbles which changes the volume of the bubble cavities, and interaction of the bubbles with the vein system during recrystallization or by bubble migration which could change the amount of air in the bubbles.

\section{Consequences for glacier permeability}

Bubbles may also influence ice permeability to water flow. Under the above conditions the vein network (Nye and Frank, 1973) would be impermeable to water cleaner than the impurity concentration needed to balance the overpressure in the bubbles. If the brine in the vein system were replaced by cleaner liquid, this liquid would partially freeze in order to regain an impurity concentration which balances the overpressure in the bubbles. The net effect would be a reduction in vein size and increased liquid in the bubbles with little consequent change in temperature. For vein sizes of tens of micrometers expected in glaciers (Lliboutry, I97I ; Raymond and Harrison, I975), one can easily verify that the production of heat in the veins by the water flow is orders of magnitudes too small to offset the loss of heat from the veins to the bubbles for even very small imbalance between impurity concentration and bubble pressure. A continuing flow of clean water into the veins would reduce the vein size to a negligibly small value such that the temperature depression from vein wall curvature 
could balance the bubble overpressure. The threshold impurity concentration required for maintenance of water flow is given by $\beta^{\prime} \Delta p /\left(R T^{2} / H\right)$ where $\Delta p$ is the overpressure. For I bar over-pressure which is of the order seen by Bader (1950) and Coachman and others (I956), this amounts to $\mathrm{IO}^{-4}$ mole fraction and is much larger than is typical of glacier ice melt or rain water.

This suggests that the vein system may normally be sealed near the surface in glacier ablation areas and may be instrumental in the existence of large surface-stream networks and lakes on some glaciers. This effect of bubbles is quite distinct from the direct blockage of veins by bubbles in contact with them which has been considered by Lliboutry (I97 I) and Raymond and Harrison (1975).

\section{Acknowledgements}

Professor E. R. LaChapelle, Suzanne Cummings Brown and Loren Chotzen helped in the field work. I particularly want to acknowledge many very helpful discussions with Professor William Harrison. The U.S. National Park Service gave permission for the work. Funding was provided by the National Science Foundation through grant numbers GA-28554 and GA-36040.

\section{REFERENCES}

Allen, C. R., and others. 1960. Structure of the lower Blue Glacier, Washington, [by] C. R. Allen, W. B. Kamb, M. F. Meier and R. P. Sharp. Journal of Geology, Vol. 68, No. 6, p. 601-25.

Bader, H. r950. The significance of air bubbles in glacier ice. Fournal of Glaciology, Vol. I, No. 8, p. 443-5 I.

Carslaw, H. S., and Jaeger, J. C. 1959. Conduction of heat in solids. Second edition. Oxford, Clarendon Press.

Coachman, L. K., and others. 1956. Gas enclosures in a temperate glacier, [by] L. K. Coachman, E. Hemmingsen and P. F. Scholander. Tellus, Vol. 8, No. 4, p. 415-23.

Corbató, C. E. 1965. Thickness and basal configuration of lower Blue Glacier, Washington, determined by gravimetry. Fournal of Glaciology, Vol. 5, No. 41, p. 637-50.

Harrison, W. D. 1972. Temperature of a temperate glacier. Fournal of Glaciology, Vol. i 1, No. 61, p. I 5-29.

Harrison, W. D. 1975[a]. A measurement of surface-perpendicular strain-rate in a glacier. Fournal of Glaciology, Vol. 14, No. 70, p. 31-37.

Harrison, W. D. 1975[b]. Temperature measurements in a temperate glacier. Journal of Glaciology, Vol. I4, No. 70, p. 23-30.

Harrison, W. D., and Raymond, C. F. I 976 . Impurities and their distribution in temperate glacier ice. Journal of Glaciology, Vol. 16, No. 74, p. 173-81.

LaChapelle, E. R. ${ }^{1} 965$. The mass budget of Blue Glacier, Washington. Journal of Glaciology, Vol. 5, No. 41, p. 6o9-23.

Lliboutry, L. A. 1971. Permeability, brine content and temperature of temperate ice. Fournal of Glaciology, Vol. 10, No. 58, p. I 5-29.

Maykut, G. A., and Untersteiner, N. 1971. Some results from a time-dependent thermodynamic model of sea ice. Fournal of Geophysical Research, Vol. 76, No. 6, p. 1550-75.

Nye, J. F., and Frank, F. C. 1973. Hydrology of the intergranular veins in a temperate glacier. Union Géodésique et Géophysique Internationale. Association Internationale d'Hydrologie Scientifique. Commission de Neiges et Glaces. Symposium on the Hydrology of Glaciers, Cambridge, 7-13 September 1969, p. 157-61.

Nye, J. F., and Mae, S. 1972. The effect of non-hydrostatic stress on intergranular water veins and lenses in ice. Fournal of Glaciology, Vol. i I, No. 6r, p. 81-ior.

Paterson, W. S. B. I97ז. Temperature measurements in Athabasca Glacier, Alberta, Canada. Journal of Glaciology, Vol. 1o, No. 6o, p. 339-49.

Raymond, C. F., and Harrison, W. D. 1975. Some observations on the behavior of the liquid and gas phases in temperate glacier ice. Fournal of Glaciology, Vol. 14, No. 71, p. 21 3-33.

Schwerdtfeger, P. I963. The thermal properties of sea ice. Fournal of Glaciology, Vol. 4, No. 36, p. 789-8o7.

Shreve, R. L., and Sharp, R. P. 1970. Internal deformation and thermal anomalies in lower Blue Glacier, Mount Olympus, Washington, U.S.A. Journal of Glaciology, Vol. 9, No. 55, p. $65-86$. 


\section{DISCUSSION}

W. F. BudD: Do you know what effects the absorption of short-wave radiation would have on the bubbles and water?

C. F. Raymond: The sample (about $10^{2} \mathrm{~mm}$ thick) was illuminated from below and the observations were made within $10 \mathrm{~mm}$ of the upper surface. The fact that no liquid appeared in the deepest observed bubbles, which were closest to the illumination source, indicates that the melting from the radiation was negligible. Calculation of the absorption using a reasonable extinction coefficient for bubbly ice also gives this conclusion.

J. W. GLEN : Is the assumption of zero ice strain around the bubble reasonable? I can see that for small times and relatively low stresses plastic strains can be neglected, but will elastic strains not reduce the build-up of pressure due to water density appreciably? This might give a change in temperature in the direction of the discrepancy between your theoretical and experimental results. Could it account for this?

Also, if I understand your theory correctly, it suggests that water may migrate from veins to bubbles during decompression, and that this might happen as ice comes towards the surface in the ablation area. Does this mean you expect an impervious layer to overlay a permeable one? Will absorbed solar radiation not deposit heat on grain boundaries and therefore tend to keep the ice permeable?

RAYMOND: During the experiment, bubble cavities containing visible water were enlarged by factors up to about ro times. It is clear that elastic strains (order $\mathrm{IO}^{-4}$ ) were negligible in comparison with this. It is possible that plastic strain-rates could have been quite high since the pressure in the bubbles was initially about 5 bar, but still the accumulated strains during the time of the experiment are likely to be small. This is supported by the observation that bubbles which did not experience melting because they were deep enough within the sample also did not experience any noticeable increase in size. If in fact the plastic strains were to happen very quickly and reduce the bubble pressures in this way, then little heat flow or melting would occur. Consequently, the sense of the effect is apparently opposite to that needed to explain the unexpectedly high liquid content of the bubbles.

Penetration of radiation into the near surface of a glacier is bound to have a substantial influence on the ice permeability. However, this effect is likely to be limited to a small number of meters; whereas, over-pressure in bubbles may exist to considerable depth in the ice where the ice is being unloaded by ablation. One must also consider the effect of vertical strain-rate on the rate of unloading at various depths. For an ablation area one might typically expect an impermeable upper layer underlain by ice which could transmit water on a fine scale, given a source of water which could feed the flow. One must keep in mind that there are several other possible mechanisms by which water-flow through the veins might be obstructed (Lliboutry, r971; Nye and Mae, 1972). 